\title{
Higher colistin dose during continuous renal replacement therapy: look before leaping!
}

\author{
Patrick M. Honore*, Rita Jacobs, Inne Hendrickx, Elisabeth De Waele, Viola Van Gorp and Herbert D. Spapen \\ See related letter by Rocco et al., http://ccforum.com/content/19/1/65
}

We read with great interest the comments of Rocco and colleagues on colistin dosing in a recent letter in Critical Care [1]. The application of continuous renal replacement therapy (CRRT) indeed offers an opportunity to prescribe very high colistin doses without exposing the patient to excess toxicity [2]. However, caution is needed before implementing this so-called CRRT 'shield' function.

First, only hyperadsorptive filters, such as the novel acrylonitryle 69 surface treated (AN69 ST (Baxter, Lyon, France)) membrane, do serve this purpose. With this type of membrane, colistin clearance increases by adsorption at both its (rapidly saturated) surface and (less easily saturated) bulk [3]. Early saturation is unlikely, and frequent membrane changes (for example, every 12 to 24 hours) are not necessary [3, 4]. This is corroborated by our experience in a small cohort of patients who tolerated colistin doses of as high as 4.5 million IU three times a day for more than 5 consecutive days. Colistin toxicity was not observed and membrane changes were never needed during the treatment period $[2,4,5]$.

Second, the functional capacity of the dialysis membrane must remain guaranteed. For this purpose, citrate is the anticoagulant of choice. Regional citrate anticoagulation has been shown to effectively counteract clogging, which ensures optimal long-term porosity [3] and, in the case of the AN69 ST filter, preserves adsorptive capacity of the membrane.

In conclusion, safe and adequate use of a higher colistin dosing regimen during CRRT requires a hyperadsorptive dialysis membrane combining convection with surface/bulk adsorption under citrate anticoagulation to consolidate membrane function.

\section{Abbreviations \\ AN69 ST: Acrylonitryle 69 surface treated; CRRT: Continuous renal} replacement therapy.

\footnotetext{
* Correspondence: patrick.honore@az.vub.ac.be

ICU Department, Universitair Ziekenhuis Brussel, Vrije Universiteit Brusse

University, 101, Laarbeeklaan, 1090 Jette (Brussels), Belgium
}

Competing interests

The authors declare that they have no competing interests.

Published online: 08 June 2015

\section{References}

1. Rocco M, Montini L, De Pascale G, Antonelli M. Dose of colistin: a work in progress? Crit Care. 2015;19:65.

2. Honoré PM, Jacobs R, Joannes-Boyau O, Boer W, De Waele E, Van Gorp V, et al. Continuous renal replacement therapy allows higher colistin dosing without increasing toxicity. J Transl Intern Med. 2013;1:6-8.

3. Honore PM, Jacobs R, Joannes-Boyau O, De Regt J, De Waele E, van Gorp V, et al. Newly designed CRRT membranes for sepsis and SIRS - a pragmatic approach for bedside intensivists summarizing the more recent advances: a systematic structured review. ASAIO J. 2013;59:99-106

4. Honore PM, Jacobs R, De Waele ED, Van Gorp V, Spapen HD. Colistin pharmacokinetics/pharmacodynamics and acute kidney injury: a difficult but reasonable marriage. Indian J Crit Care Med. 2014;18:415-6.

5. Honoré PM, Jacobs R, Lochy S, De Waele E, Van Gorp V, De Regt J, et al. Acute respiratory muscle weakness and apnea in a critically ill patient induced by colistin neurotoxicity: key potential role of hemoadsorption elimination during continuous venovenous hemofiltration. Int J Nephrol Renovasc Dis. 2013;6:107-11.

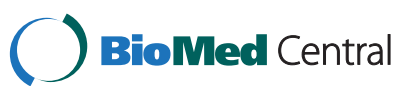

c 2015 Honore et al.; licensee BioMed Central. This is an Open Access article distributed under the terms of the Creative Commons Attribution License (http://creativecommons.org/licenses/by/4.0), which permits unrestricted use, distribution, and reproduction in any medium, provided the original work is properly credited. The Creative Commons Public Domain Dedication waiver (http://creativecommons.org/publicdomain/zero/1.0/) applies to the data made available in this article, unless otherwise stated. 